\title{
ESTRUTURA DO SETOR INDUSTRIAL PESQUEIRO NO ESTADO DE SANTA CATARINA
}

\author{
H.A. ANDRADE \\ CTTMar - Universidade do Vale do Itajaí (FACIMAR/UNIVALI) \\ Rua Uruguai 458, Cx.P. 360, Itajaí, SC - CEP 88.302-202 \\ humber@univali.rct-sc.br
}

\begin{abstract}
RESUMO
A estrutura do centro pesqueiro industrial de Santa Catarina sofre contínuas mudanças devido a uma série de fatores biológicos, econômicos, sociais e políticos. É muito importante para uma administração pesqueira adequada e para a tomada de decisões econômicas, o conhecimento da estrutura do parque industrial e da variabilidade das capturas de pescado e dimensões das frotas. Dessa forma, este trabalho teve por objetivo verificar a variabilidade da captura anual de 1983 a 1990, e identificar a estrutura física atual do setor pesqueiro industrial de Santa Catarina. A base de informações analisada foi obtida mediante a visita periódica às indústrias de pesca, e também através de levantamento dos dados históricos disponíveis. A pesca industrial é a principal fonte de pescado em Santa Catarina. Nos últimos anos a frota industrial tem aumentado sua produção, enquanto que a produção artesanal, vem sofrendo um decréscimo contínuo. As frotas de traineiras, arrasto de parelhas e de tangones (camaroeiros) são as frotas mais numerosas. A maioria das embarcações tem de 17 a 27 metros de comprimento e opera com 5 a 15 tripulantes a bordo. No estado de Santa Catarina as principais estruturas portuárias pesqueiras estão localizadas nas cidades de Itajaí e Navegantes. Apesar do incremento generalizado na produção pesqueira, há sérios problemas ainda sem solução: a) É necessário a diversificação dos produtos direcionados ao consumo humano; b) Falta uma maior tecnologia de beneficiamento do pescado; e c) $O$ manejo inadequado a bordo resulta em um produto pesqueiro de baixa qualidade.
\end{abstract}

PALAVRAS CHAVE: Pesca Industrial; Frota Pesqueira Catarinense; Santa Catarina, Brasil

\section{STRUCTURE OF THE INDUSTRIAL FISHERY IN SANTA CATARINA STATE}

\begin{abstract}
The structure of the industrial fishery center of Santa Catarina changes continuously due to several biologic, economic, social and politic factors. It is very important for suitable fishery administration and economic decisions to get information about the structure of fishery industries and about the variations of the system, such as changes on the catch and fleet dimensions. Thus, the objectives of this work was verify the annual catch variability from 1983 to 1990 , and identify the nowadays physical structure of the industrial fishery section of Santa Catarina. The information base was obtained from periodical visits to the fishing industries, and also from historical data available to analysis. The industrial sector is the main source of fishery products in Santa Catarina. In the last years the industrial fleet have been increasing the production, while the artisanal production, has been decreasing continuously. The purse seine, paired and shrimp trawlers are the most numerous fleets. Most of the ships are 17 to 27 meters length and operates with 5 to 15 fishermen onboard. In the Santa Catarina state the main fishery harbor structures are located in the Itajai and Navegantes cities. Despite the general increase of fishery production, there are several problems waiting for solutions: a) It is necessary a diversification of the products to human consume; b) There is a lack of technology in the product processing; and c) The careless management onboard results in a low quality fishery product.
\end{abstract}

KEYWORDS: Industrial Fishery; Fishing Fleet of Santa Catarina; Santa Catarina, Brazil 


\section{INTRODUÇÃO}

A estrutura pesqueira catarinense é bastante diversificada, e tem sua produção baseada em diversas espécies de peixes, crustáceos e moluscos, capturados por diferentes tipos de embarcações e métodos de pesca (CEPSUL/IBAMA, 1994 a e 1994 b; Andrade, 1998 a). A dinâmica estrutural quanto às formas de exploração dos recursos, composição da frota e do parque pesqueiro, é condicionada por fatores biológicos, ecológicos, sociais, econômicos e políticos (Stevenson et al., 1982). Essa dependência múltipla de fatores variáveis, faz com que a estrutura industrial pesqueira seja bastante dinâmica. A cada ano ocorrem, por exemplo, transferências de embarcações de uma frota para outra, com modificações para a atuação em outra pescaria (Andrade, 1998 a). Dessa forma, recentemente houve desenvolvimento de algumas frotas e regressão de outras. As frota de caceio e espinheleiros, por exemplo, mostraram um crescimento grande no início da década de 90 (CEPSUL/IBAMA, 1994 a e b; Andrade, 1998 a).

O conhecimento das modificações da frota pesqueira, e da estrutura do complexo pesqueiro industrial, quanto a captura e beneficiamento de pescado, constitui um fator importante para a administração pesqueira e o direcionamento econômico do mercado. Neste trabalho, essa necessidade foi abordada através de um diagnóstico setorial e periódico, sobre o comportamento dos fatores de produção integrados pela frota pesqueira e o parque industrial nas cidades de Itajaí e Navegantes. A pesquisa foi baseada nestas cidades, uma vez que as mesmas são os principais portos pesqueiros do estado.

\section{MATERIAL E MÉTODOS}

As informações analisadas foram obtidas através de visitas periódicas às fábricas de pesca e zona portuária, com a aplicação de questionários direcionados a pescadores, armadores, gerentes e proprietários de indústrias envolvidas com o setor pesqueiro. Foi abordado cerca de $70 \%$ do número de indústrias envolvidas na captura e processamento de pescado nas cidades de Itajaí e Navegantes. Foi feito também um levantamento histórico das informações disponíveis em boletins e informes do IBAMA. As informações existentes no IBAMA são na grande maioria provenientes do Posto de Controle e Fiscalização do IBAMA (POCOF). É importante ressaltar que os dados disponíveis no POCOF são obtidos mediante a emissão de notas fiscais no momento do descarregamento e pesagem do pescado e da renovação de licenças de pesca. Além disso, foram consultados também anuários e guias disponíveis do setor pesqueiro industrial.

\section{RESULTADOS E DISCUSSÃO}

\section{PRODUÇÃO PESQUEIRA INDUSTRIAL}

No litoral de Santa Catarina, a atividade pesqueira é realizada tradicionalmente em escala artesanal e industrial. A pescaria artesanal é efetuada com pequenas embarcações, em regiões costeiras e estuarinas, enquanto que a pesca industrial abrange, além das regiões costeiras, as regiões oceânicas mais profundas, e é realizada por embarcações de maior tamanho, autonomia de navegação e tecnologia. Historicamente a produção industrial supera em muito a da pesca artesanal (Figura 1).

A produção pesqueira artesanal que manteve-se entre 20 e 30 mil toneladas anuais até 1984, apresentou posteriormente uma queda acentuada até cerca de 10 toneladas em 1986. A partir desse ano a produção artesanal tem mostrado uma tendência de decréscimo mais suave (Figura 1). É evidente a situação crítica e a tendência de colapso da pesca artesanal, já que a partir de meados da década de 80 a produção foi sempre inferior a 
12 mil toneladas anuais. Apesar da menor contribuição econômica dessa modalidade em termos de volume de pescado, cabe ressaltar sua importância social, uma vez que a pescaria artesanal é freqüentemente a atividade única ou principal na sustentação de famílias de baixa renda no litoral catarinense.

Ao contrário da produção artesanal, a produção industrial mostrou grandes oscilações, porém, sem tendências contínuas de decréscimo (Figura 1). Após um declínio acentuado no início da década de 80 , houve um incremento acentuado do peso total descarregado até 1985. Posteriormente houve um novo declínio até 1987, e novamente um incremento gradativo até 1993 (Figura 1). Apesar das oscilações, é aparente uma tendência geral de incremento da produção a partir de 1981. É importante ressaltar que a tendência de incremento da produção industrial a partir do início da década de 80 não é derivado de aumento da abundância dos recursos pesqueiros explorados, e sim de aumento no esforço de pesca e no número de descarregamentos realizados em Santa Catarina (Andrade, 1998a).

Comparativamente, a tendência de crescimento dos descarregamentos da pesca industrial em relação à pesca artesanal teve

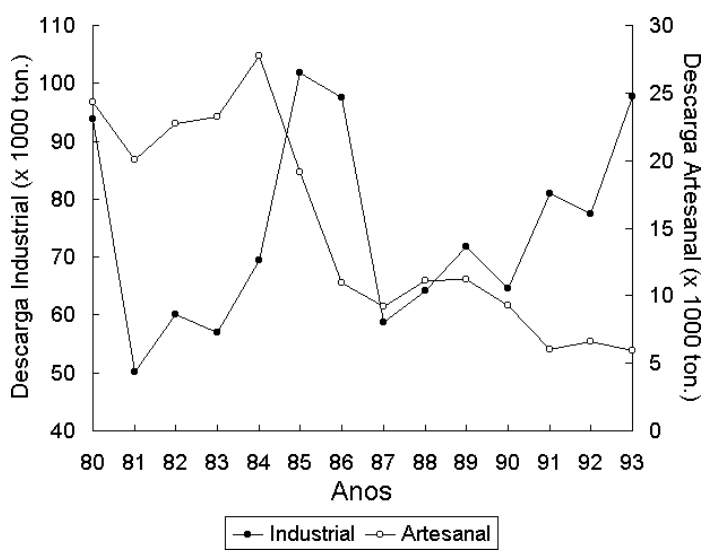

Figura 1: Total de pescado descarregado (toneladas) pelas frotas artesanal e industrial no estado de Santa Catarina entre os anos de 1980 e 1993 (Fonte de Dados: CEPSUL/IBAMA, 1994 a e 1994 b). um grande salto entre 1984 e 1986, quando a contribuição percentual da pesca industrial passou de cerca de $70 \%$ do total a níveis superiores a $85 \%$ (Figura 2). Posteriormente não houveram modificações acentuadas nesse quadro até o início da década de 1990, quando a pescaria industrial voltou a apresentar um novo crescimento relativo. Em 1993 a pesca industrial passou a compor mais de $94 \%$ da produção pesqueira no estado de Santa Catarina (Figura 2). Entretanto, em termos de movimentação monetária, a pesca industrial foi responsável por somente $92,5 \%$ do total, uma vez que em média o valor de comercialização dos produtos da pesca artesanal é maior (Neto \& Grumann, 1995).

As grandes variações no mercado, com tendência de aumento da importância da pesca industrial em termos do peso total descarregado, refletem basicamente dois processos: a) a tendência de colapso da pesca artesanal; e b) o próprio incremento do total capturado pela pesca industrial entre 1984 e 1985, e a partir de 1987 (Figura 1). Entretanto, é necessário cautela na interpretação de resultados de comparações entre as pescarias artesanais e industriais. A produção artesanal catarinense é realmente derivada unicamente da frota artesanal sediada no estado, enquanto que a

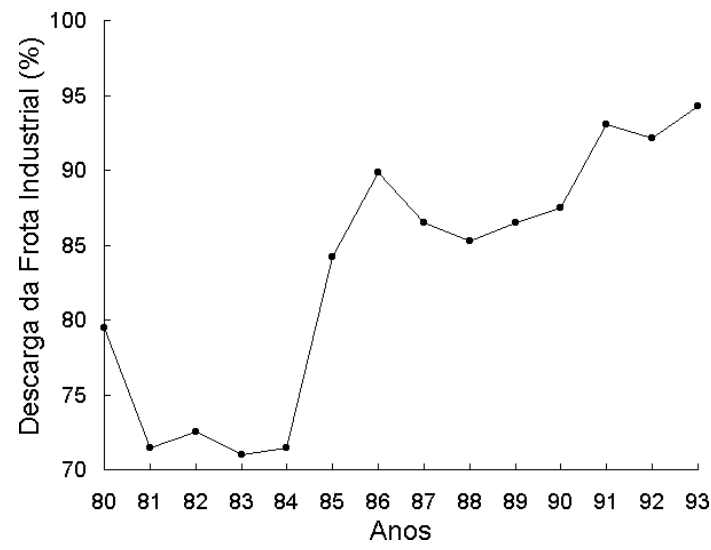

Figura 2: Percentual do total de pescado descarregado pela frota industrial no estado de Santa Catarina entre os anos de 1980 e 1993 (Fonte de Dados: CEPSUL/ IBAMA, 1994 a e 1994 b). 
produção industrial inclui descarregamentos de frotas sediadas em outros estados, mas que descarregaram em Santa Catarina. $O$ contrário também ocorre, em determinadas situações embarcações catarinenses realizam descarregamentos em outros portos pesqueiros da região sudeste. Outra questão que deve ser considerada, é que reconhecidamente há insuficiência de coletores, principalmente para a pesca artesanal, o que gera uma defasagem na coleta dos dados e uma subestimação da produção dessa modalidade de pesca (CEPSUL/IBAMA, 1994 a e 1994 b). O desmantelamento do sistema de coleta de dados é provavelmente um dos principais fatores para a queda de produção observada para o setor artesanal. Um outro fator de menor importância, mas que deve ser mencionado, é que a produção artesanal escoa livremente em uma economia informal desde o pescador ao consumidor, sem qualquer tipo de emissão de notas fiscais, o que dificulta 0 controle da produção.

\section{COMPOSIÇÃO DA FROTA PESQUEIRA}

No diversificado parque pesqueiro industrial catarinense, destacam-se as frotas de traineiras, camaroeiros, parelhas, atuneiros e caceio como as mais numerosas, compondo mais de $90 \%$ do total de embarcações sediadas no estado (Figura 3). No entanto é importante mencionar que houveram discordâncias quanto às dimensões das frotas operantes entre os dados obtidos na pesquisa realizada (Figura 3a) e as informações fornecidas pelo POCOF/IBAMA (Figura 3b). A principal diferença ocorreu para a frota de arrasteiros simples. Os dados obtidos na pesquisa realizada indicam que somente $2 \%$ da frota é composta por arrasteiros simples. No entanto segundo os dados disponíveis do POCOF/IBAMA, essa frota seria a $4^{\mathrm{a}}$ maior do estado, correspondendo a cerca de $15 \%$ da frota total. As diferenças quanto as dimensões das frotas de caceio e atuneiros devem também ser ressaltadas. Na pesquisa reali-
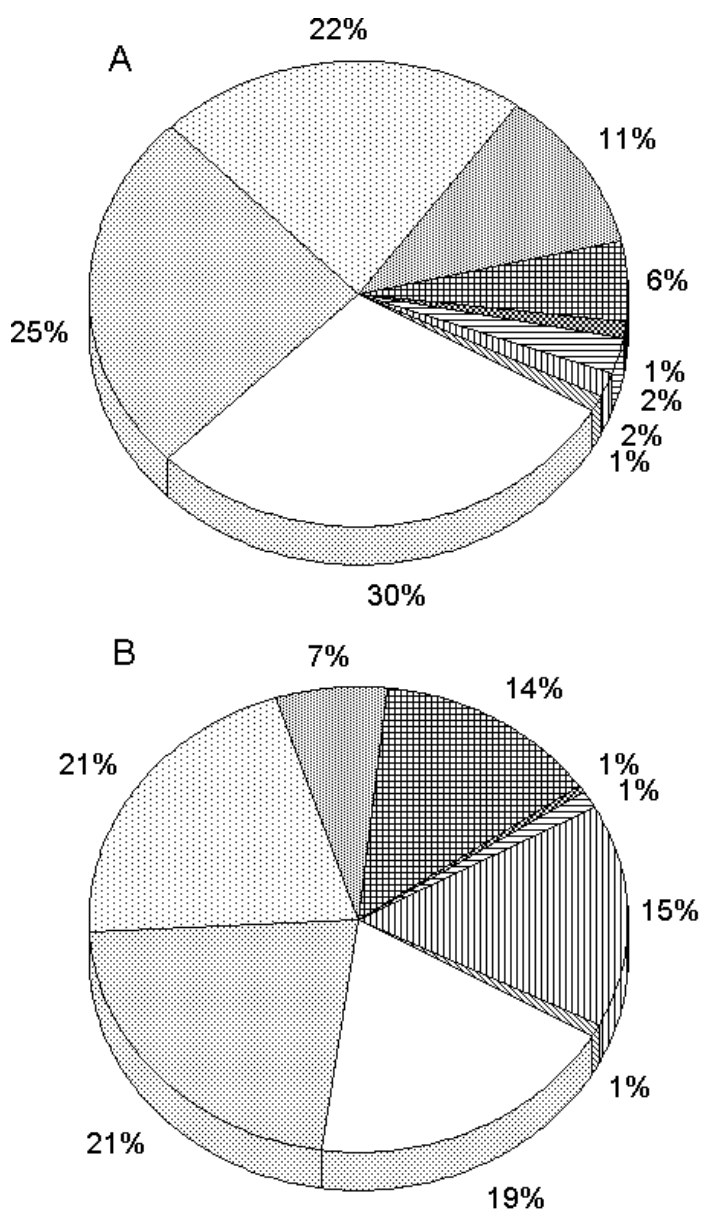

\begin{tabular}{|c|c|c|}
\hline$\square$ Traineiras & م Camaroeiros & : Parelhas \\
\hline Atuneiros & 囲 Caceio & จ Linheiros \\
\hline 目 Espinheleiros & 四 Arr. Simples & ⿴囗 Pargueiros \\
\hline
\end{tabular}

Figura 3: Composição percentual da frota sediada no Estado de Santa Catarina. (A) Dados obtidos mediante pesquisa de campo do autor; (B) Dados obtidos mediante levantamento histórico de informações do POCOF/ IBAMA (Fonte de Dados: CEPSUL/IBAMA, 1994 b).

zada, a frota atuneira é mais numerosa, enquanto que as informações disponibilizadas pelo POCOF/IBAMA indicam o contrário, que a frota de caceio é maior (Figura $3 a$ e b). Todas estas diferenças poderiam ser resultado de que os dados de fiscalização são mais abrangentes, uma vez que são obtidos medi- 
ante o acompanhamento completo de todos os descarregamentos realizados, através de notas fiscais. Entretanto, ao longo do trabalho foram realmente avistados muito poucos barcos arrasteiros simples, docados ou em atividade, sendo difícil crer que a grande diferença encontrada para essa categoria seja resultado de erro amostral na pesquisa realizada. Uma possível explicação é que nos dados do POCOF, embarcações de tangones (camaroeiras) foram denominadas de arrasteiros simples ou de peixe, quando não tiveram os camarões como alvo de pescaria. De qualquer forma, os números existentes são controvertidos. Em 1995 o Sindicato da Indústria da Pesca de Itajaí (SINDIPI) apontava a existência de cerca de 425 embarcações pesqueiras no litoral catarinense. Dessas embarcações, cerca de $20 \%$ seriam traineiras e $9,5 \%$ atuneiros. Como pode ser observado, estes valores não são iguais aos apontados tanto pelos relatórios do CEPSUL/IBAMA, quanto pelo levantamento realizado mediante entrevistas junto aos empresários (Figuras 3a e b). Essas discordâncias refletem a grande dinâmica das frotas operantes e a evidente falta de monitoramento. De qualquer forma, o que é importante e deve ser ressaltado é o domínio nas últimas décadas, de traineiras, camaroeiros e parelhas entre as embarcações pesqueiras sediadas em Santa Catarina (Figura 3).

\section{CARACTERÍSTICAS DAS EMBARCA- ÇÕES}

Os dados sobre a dimensão das embarcações pesqueiras catarinenses, levantados mediante visitações e entrevistas foram bastante semelhantes aos disponíveis em relatórios de pesca do CEPSUL/IBAMA (1994a e 1994b). A grande maioria das frotas tem embarcações com um comprimento entre 17 e 27 metros. Uma exceção são as embarcações dedicadas à pescaria de espinhel, bem maiores, com um comprimento médio de cerca de 45 metros (Figura 4). A pesca de espinhel é normalmente realizada em águas bem mais profundas, na região do talude continental e mesmo da bacia oceânica, de forma que há realmente necessidade de emprego de embarcações de maior porte. É importante mencionar que as pescarias de caceio $\mathrm{e}$ de linheiros, também são freqüentemente re-

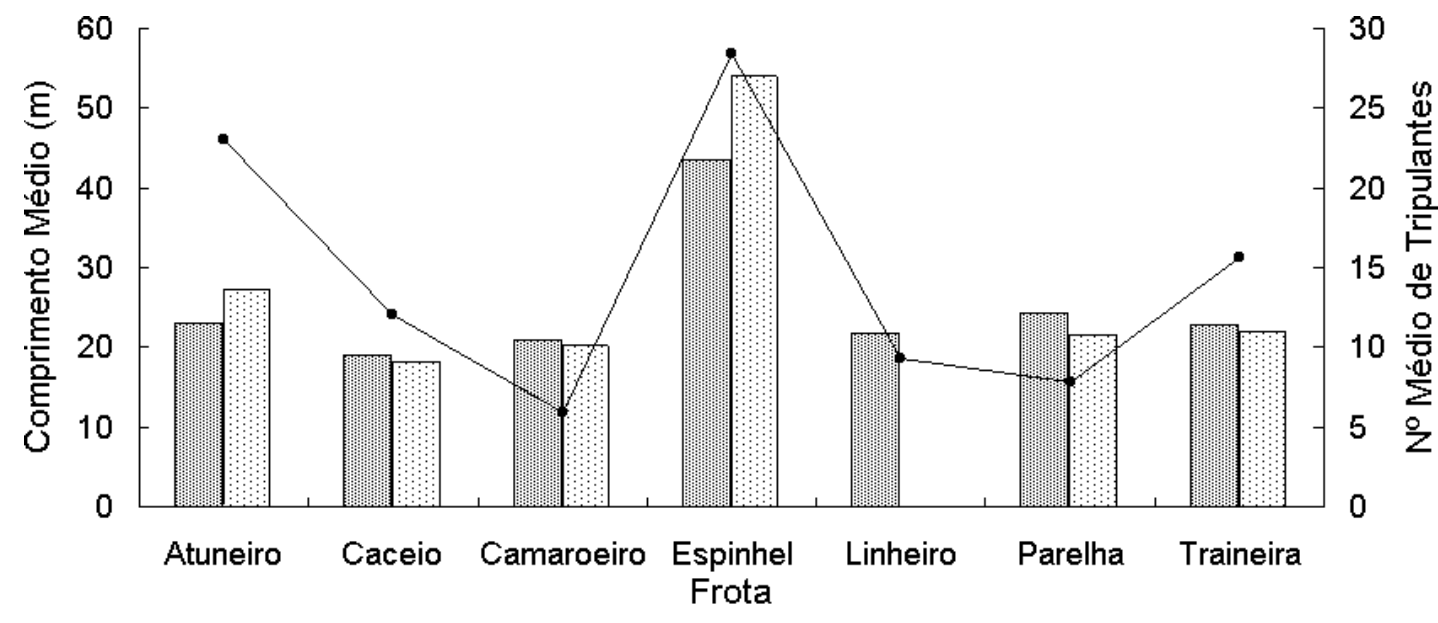

dados levantados em 1995 dados de 1993 (CEPSUL/BAMA) - Tripulaçăo

Figura 4: Comprimento médio por frota das embarcações pesqueiras catarinenses. Dados levantados nesse trabalho e fornecidos pelo CEPSUL/IBAMA (Fonte de Dados: CEPSUL/IBAMA, 1994 b). 
alizadas em regiões de grandes profundidades. No entanto, a dimensão das embarcações é pequena (Figura 4), o que faz dessas pescarias, as de maior risco. Justamente as embarcações de caceio, que normalmente navegam por águas mais profundas, apresentam as menores dimensões $(<18 \mathrm{~m})$ e o pior aspecto quanto à conservação. Essa frota contém muitos barcos velhos e sucateados.

A variação quanto ao número de tripulantes é aproximadamente proporcional às variações quanto as dimensões das frotas. Uma exceção é a frota atuneira de vara e iscaviva, que trabalha com um número relativamente maior de tripulantes (Figura 4). Essa característica é um reflexo direto da pescaria, na qual quanto maior o número de pescadores, maior a capacidade de captura (Andrade, 1998 b).

\section{PARQUE PESQUEIRO INDUSTRIAL}

A grande maioria da produção industrial catarinense é proveniente dos portos pesqueiros de Itajaí e Navegantes, responsáveis em 1993 respectivamente por 63,6\% e 31,7\% da produção total (Figura 5). Devido à proximidade geográfica e aos enlaces sociais e eco-

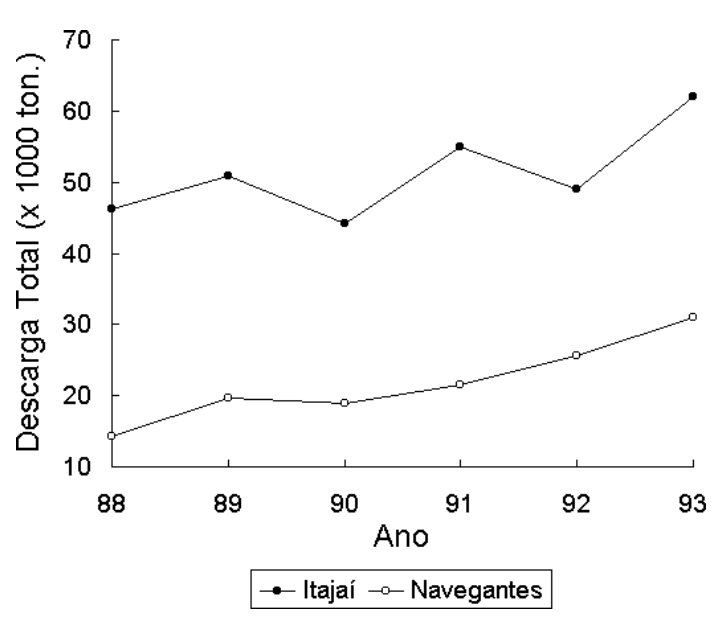

Figura 5: Descarregamento anual de pescado nos portos de Itajaí e Navegantes, no estado de Santa Catarina (Fonte de Dados: CEPSUL/IBAMA, 1994 a e 1994 b). nômicos, as movimentações operacionais de descargas e a comercialização de pescado nos portos de Itajaí e Navegantes são estreitamente relacionadas e não podem ser avaliadas isoladamente. Um reflexo dessa interação dinâmica é a semelhança entre as variações anuais de captura, com tendência de crescimento suave de 1988 a 1993 (Figura 5). Nessa tendência de incremento, destacase a cidade de Navegantes, que dobrou sua produção de 1988 a 1993.

A destacada produção das cidades de Itajaí e Navegantes em Santa Catarina está associada evidentemente aos grandes parques industriais locais, que correspondem conjuntamente a mais de $75 \%$ do complexo pesqueiro estadual (Figura 6). A estrutura industrial é complexa, havendo empresas estritamente catarinenses, e outras que são filiais ou possuem filias em outros estados.

De forma geral, as indústrias estão basicamente envolvidas em atividades de captura e comércio, o que implica em alguns casos no processamento do pescado. A grande maioria das indústrias, atua tanto na captura como no comércio, enquanto que uma pequena quantidade de empresas atua somente no comércio do pescado (Figura 7). Destas últi-

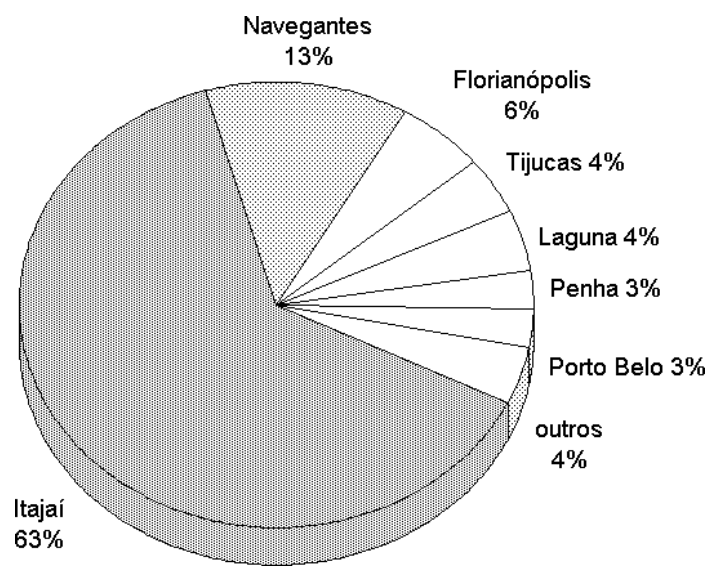

Figura 6: Participação percentual atual das cidades de Santa Catarina quanto ao número de indústrias diretamente envolvidas na produção pesqueira industrial (Fonte de Dados: Oliveira, 1995). 
mas, a grande maioria das indústrias faz algum tipo de beneficiamento da matéria prima antes da comercialização.

É importante ressaltar que nem todas as embarcações pesqueiras são também propriedade dos empresários que detém o patrimônio das indústrias pesqueiras. Muitas embarcações são de empresários conhecidos como "armadores de pesca", os quais não possuem qualquer tipo de estrutura de descarga e comercialização de pescado.

\section{COMÉRCIO DO PESCADO}

Os principais produtos fornecidos pelas indústrias instaladas na região são: a) sardinha, nas formas in natura, congelada e enlatada; b) camarões vermelho, sete-barbas e rosa; c) tunídeos, principalmente bonito listado; d) cações, principalmente cação anjo; e) peixe demersais, destacadamente, abrótea, corvina, linguado e pescadas; f) diversas espécies demersais, na forma de mistura; g) tainha; h) lulas.

O preço do produto sofre oscilações dependentes do mercado em função de épocas de maior consumo (veraneio), das variações de abundância dos estoques e das próprias safras das pescarias decorrentes dos ciclos anuais das espécies. Entretanto, em uma abordagem grosseira para o período de



Figura 7: Distribuição das atividades desenvolvidas pela indústria pesqueira no litoral catarinense.
1994/95, estima-se que no descarregamento o preço da sardinha congelada oscilou entre $\mathrm{R} \$ 0,60$ e $\mathrm{R} \$ 0,75$, enquanto que a sardinha in natura teve seu preço entre $R \$ 0,25$ e $R \$ 0,30$ o quilo. O preço do quilo do bonito listado variou entre $R \$ 0,60$ e $R \$ 0,70$. Peças de atuns do gênero Thunnus, tiveram seu preço variando de $R \$ 0,80$ a $R \$ 1,20$ o quilo. O quilo do cação foi negociado em média a $R \$ 1,50$. $O$ camarão rosa é sem dúvida o recurso de maior valor, com preços variando entre $R \$ 13,00$ e $\mathrm{R} \$ 18,00$, enquanto que os preços por quilo dos demais camarões mantiveram-se entre $\mathrm{R} \$ 1,00$ e $\mathrm{R} \$ 4,00$.

O comércio do pescado capturado pela frota industrial é basicamente dirigido para o mercado interestadual e internacional. Existe também uma comercialização razoável entre empresas dentro de Itajaí e Navegante mesmo, porém os destinatários finais dos produtos são normalmente localidades fora de Santa Catarina. Assim, a indústria pesqueira catarinense destina somente cerca de $10 \%$ de sua produção para o mercado interno (Neto \& Grumann, 1995). A comercialização entre as indústrias de Santa Catarina e outras localidades nacionais e internacionais é baseada em uma pequena gama de produtos pesqueiros, entre os quais destacam-se a sardinha, atuns e camarões. Em geral, cerca de $70 \%$ dessa produção passa por algum tipo de beneficiamento em indústrias antes de ser repassada ao consumidor. Os demais 30\% passam por intermediários e são colocados in natura no mercado de consumo (Neto \& Grumann, 1995).

Várias localidades nacionais compram produtos pesqueiros de empresas catarinenses, entre elas destacam-se os estados de São Paulo, Rio de Janeiro, Rio Grande do Sul e Paraná. Porém é válido registrar a existência de comércio com estados fora do eixo sudeste-sul, como Mato Grosso do Sul, Alagoas e Pernambuco. O escoamento da produção pesqueira catarinense para o mercado nacional é feito basicamente por transporte rodoviário. No transporte são usados 
veículos próprios da indústria, ou são contratados serviços de fretes, o que é mais comum, uma vez que existem várias empresas de pescado que não possuem uma frota rodoviária adequada. $O$ valor do frete é variável segundo o peso em toneladas e a distância a ser percorrida.

Quanto ao mercado internacional, a grande maioria das exportações de pescado é baseada na produção de atuns e afins, mais especificamente, em tunídeos de maior porte (espécies dos gêneros Thunnus e Xiphias), capturados pela frota espinheleira. Os principais compradores são o Japão, alguns países da Europa, como a Espanha e a Inglaterra, e ainda países vizinhos, como a Argentina. As exportações são feitas basicamente por navios, através de agências marítimas.

\section{PERDAS OCORRIDAS ENTRE A PESCA E A COMERCIALIZAÇÃO}

Apesar da frota ser dotada de porões com urnas para o acondicionamento do pescado, a falta de cuidados no processo de pesca e, principalmente, no acondicionamento e conservação do pescado a bordo, é um fator que contribui muito para perdas na produção. Além do manuseio deficiente, o uso de proporções inadequadas de gelo e volume de pescado é também um dos fatores que determinam que uma parcela do pescado descarregado, seja de baixa qualidade.

O rejeito de pesca é outro fator que contribui em muito para perdas e esperdícios de pescado. Esse fator é particularmente importante nas pescas de arrasto de fundo (camaroeiros, arrasteiros simples e parelhas) (Haimovici \& Palacios Macieira, 1981; Haimovici \& Habiaga, 1982). Uma grande quantidade de peixes é descartada e lançada ao mar a cada lance. No caso da pesca de arrasto de peixes, o rejeito é freqüentemente bem maior do que a captura total aproveitada (Haimovici \& Mendonça, no prelo). Para a pesca de camarão, estes autores destacam ainda que um outro aspecto importante é que a maioria do rejeito é freqüentemente constituído de juvenis de espécies de interesse comercial. Quase a totalidade desses organismos retornam ao mar já mortos ou sem condições de recuperação e sobrevivência.

O esperdício derivado dos rejeitos de pesca, é um problema que não tem uma solução muito simples. Uma alternativa seria investir em linhas de produção de alimentos de baixa qualidade ou rações animais, para maior aproveitamento do rejeito. Porém, teria que haver uma solução para o problema de armazenamento a bordo de um produto de baixa rentabilidade, que estaria ocupando um espaço que seria destinado ao pescado próprio à alimentação humana, que alcança meIhor preço no mercado. O armazenamento de peixes pequenos do rejeito para a transformação em farinha de peixe somente é feito em poucos casos e no final da viagem, quando não há mais perspectivas de boa captura.

Outra possibilidade de amenizar a problemática do rejeito seria intervir nas redes de pesca através de legislações quanto ao tamanho e formato das malhas. Malhas quadradas sem dúvida proporcionariam uma menor captura de rejeito do que as malhas tradicionais. Porém essa também não é uma questão simples, sendo de difícil aplicação na prática, uma vez que haveria forte resistência por parte dos pescadores contra medidas administrativas desse tipo.

Além das perdas discutidas acima, há ainda perdas relacionadas à transformação e ao beneficiamento do pescado. A desqualificação da mão-de-obra e o uso de equipamentos de baixa qualidade (ex: descascadeiras rudimentares de camarão) são também fatores importantes que contribuem para o esperdício do processo pesqueiro industrial.

\section{PROBLEMAS DO SETOR PESQUEIRO INDUSTRIAL}

Houveram nas últimas décadas, progressos no setor industrial pesqueiro brasilei- 
ro, com alguma diversificação da produção, aumento da comercialização interna e da exportação. No cenário nacional, o setor industrial pesqueiro catarinense destaca-se por possuir uma frota jovem e diversificada. No estado, a atividade de pesca da frota industrial, constituída por cerca de 400 barcos, é exercida ao longo de toda a costa das regiões Sudeste e Sul. Apesar de todos estes pontos positivos, o saldo global do setor industrial não é satisfatório. A atual diversidade de produtos não pode ser considerada como suficiente. Em Santa Catarina a industrialização de pescado tem se apoiado basicamente na utilização tradicional de sardinhas e camarões. Essa limitação da diversidade de produtos tem sido negativa para o setor industrial, em virtude da falta de matéria-prima para o processamento. Assim, uma parcela considerável das instalações industriais vêm operando com grande ociosidade. Um paliativo para o problema poderia ser o aproveitamento e a melhoria do processamento de espécies cultivadas e de recursos pesqueiros alternativos.

A falta de agregação de valores aos produtos pesqueiros é um dos problemas das linhas de produção locais. São descarregadas espécies consideradas como pescados nobres a nível mundial, entretanto freqüentemente ao invés de haver qualquer tipo de processamento que resulte em agregação de valor e rendimento líquido, o produto é comercializado na grande maioria das vezes in natura. Mesmo para os recursos de baixo preço de comercialização, certamente o processamento alimentício para a agregação de valores, como por exemplo a produção de "surimi" (carne de peixe extrudada), certamente seria uma alternativa de incremento do rendimento econômico.

Do ponto de vista da exploração dos recursos pesqueiros, é notório que os níveis atuais de rendimento e captura das espécies tradicionalmente utilizadas pela indústria, não permitem cálculos otimistas quanto às possibilidades de incrementar o processo industrial (CEPSUL/IBAMA, 1993). Essa situação obriga à um freqüente escoamento de divisas, via importação de pescado de outros países, para alimentação de nossas linhas de produção pesqueiras regionais.

A situação crítica atual é em grande parte decorrente de que nos anos 70 , em virtude da política governamental de incentivos fiscais, instalou-se no país um grande parque industrial super dimensionado, que não obteve no entanto, a projeção desejada. Na época havia relativa abundância de matéria prima e especulou-se erroneamente que a mesma se manteria e que haveria até possibilidades de expansão, mesmo que se aumentasse as linhas de produção e por conseqüência o esforço pesqueiro. Houve uma grande defasagem entre as reais possibilidades de rendimento sustentável de pesca e a capacidade de processamento de pescado, o que resultou numa sobrecapitalização. Esse erro foi e continua sendo um exemplo crasso do prejuízo causado pela falta de conhecimentos de biologia pesqueira, erro esse, pelo qual o setor industrial paga ainda atualmente. Foi criado um problema social que se propaga ao longo dos anos enquanto o setor pesqueiro industrial sufoca-se sob o peso de sua grande estrutura ociosa. Neto \& Grumann (1995) argumentam que o excessivo endividamento das empresas e as taxas de juros muito elevadas para investimentos de longo prazo penalizaram severamente as indústrias pesqueiras locais. Os autores concluem que estes fatores, aliados aos períodos de crise de captura, acabaram por levar alguns empreendimentos à insolvência.

A abertura do mercado entre países vizinhos da América do Sul através do MERCOSUL, traz sem dúvidas perspectivas positivas para uma série de áreas industriais nacionais, como para as produtoras de veículos, motores, eletrodomésticos e mesmo brinquedos. Ao contrário do efeito produzido pelo MERCOSUL sobre essas linhas de produção, essa abertura de mercado traz perspectivas negativas para o setor pesqueiro industrial. Atualmente a economia pesqueira nacional 
está fragilizada pela crise que atravessa, e não apresenta as condições competitivas necessárias (Neto \& Grumann, 1995).

\section{CONCLUSÕES}

1) A tendência de aumento da importância da pesca industrial em termos de produção entre 1981 e 1993, reflete dois processos: a) a tendência de colapso da pesca artesanal e do sistema de coleta de informações a ela direcionado; e b) o incremento, ainda que suave, do total capturado pela pesca industrial a partir de 1981 .

2) As frotas de traineiras, e de arrasteiros de parelhas e tangones (camaroeiros), são as mais numerosas em Santa Catarina.

3) A grande maioria das embarcações tem comprimento entre 17 e 27 metros e opera com 5 a 15 tripulantes. Como exceções têmse as frotas de espinhel e de vara e isca-viva, as quais operam com mais de 20 tripulantes. No caso da frota de espinhel, as embarcações tem comprimento superior a 40 metros.

4) O complexo portuário de Itajaí e Navegantes é o principal do estado, sendo responsável por mais de $75 \%$ da produção pesqueira em Santa Catarina. Nestes portos, a maioria das empresas pesqueiras (mais de $75 \%$ ) realizam tanto a captura como o comércio do pescado, enquanto que as demais somente comercializam produtos pesqueiros.

6) Há uma série de problemas no setor pesqueiro industrial que devem ser solucionados: a) a diversificação dos produtos para o consumo humano não é suficiente; b) falta uma maior tecnologia de beneficiamento do pescado para a agregação de valores; e c) a má qualidade na manipulação e estocagem do pescado a bordo promove perda de qualidade do pescado.

\section{AGRADECIMENTOS}

À Fundação Banco do Brasil que financiou e propiciou a execução desse trabalho.

\section{REFERÊNCIAS BIBLIOGRÁFICAS}

Andrade, H. A. 1998 a. A Produção da Pesca Industrial em Santa Catarina. Notas Técnicas da Faculdade de Ciências do Mar. neste volume.

Andrade, H. A. 1998 b. Problemática Sobre a Amostragem de Desembarques Comerciais de Pescados: O Estudo do Caso da Amostragem do Bonito Listado em Itajaí. neste volume.

CEPSUL/IBAMA, 1993. Relatório da III Reunião do Grupo Permanente de Estudos (GPE) sobre Peixes Demersais. Coleção Meio Ambiente. Série Estudos de Pesca no 8.93 p.

CEPSUL/IBAMA, 1994 a. Informe sobre os Desembarques Controlados de Pescados no Estado de Santa Catarina, nos Anos de 1988 a 1992. Itajaí. 101 pp.

CEPSUL/IBAMA, 1994 b. Desembarques Controlados de Pescados. Estado de Santa Catarina - 1993. Coleção Meio Ambiente. Série Estudos - Pesca, № 14., IBAMA, Brasília. 132 pp.

Haimovici, M. \& R. Palacios Macieira. 1981. Observações sobre a Seleção a Bordo e Rejeição na Pesca de Arrasto de Fundo no Rio Grande do Sul. Anais do Segundo Congresso Brasileiro de Engenharia de Pesca, Recife: 401-411.

Haimovici, M. \& R. G. P. Habiaga. 1982. Rejeição a Bordo na Pesca de Arrasto de Fundo no Litoral de Rio Grande do Sul num Cruzeiro de Primavera. Sér. Dóc. Téc. Oceanografia, FURG, №. 2:1-14. Rio Grande.

Haimovici, M. \& J. T. Mendonça. 1997. Descartes na Pesca de Arrasto de Tangone Dirigida ao Linguado e ao 
Camarão no Sul do Brasil. Atlântica, 18, no prelo.

Neto, F. M. O. \&, A. Grumann. 1995. Cadeias Produtivas. Programa: Aqüicultura e Pesca. EPAGRI. 64 pp.
Oliveira, M. T. 1995. Anuário Pesca e Pescado - Guia ao Setor Pesqueiro. vol. I, ano I, $167 \mathrm{pp}$.

Stevenson, D.; Pollnac, R. \& Logan, P. A. 1982. A Guide for the Small-Scale Fishery Administrador: Information from the Harvest Sector. ICMRD. USA. 